\title{
Improving the health of people with disabilities: what must we do?
}

\author{
David Gordon ${ }^{7}$
}

The moral and universal obligation to care for the health of all, including those with disabilities, is not simply part of human culture, it is required by international treaty; for example, the necessity of care for the disabled is set out in Article 25 of the Universal Declaration of Human Rights [1]. The Constitution of the World Health Organization defines health (in the words of Andrija Štampar) as " ... a state of complete physical, mental and social well-being and not merely the absence of disease or infirmity" [2], and the challenge is to ensure that those who are disabled are, as far as possible, in a holistic state of wellbeing. Suffering may have a meaning for us all [3], but that does not absolve us from the obligation to work to relieve suffering, and much of that relief of the suffering of disabled people will be by caring for their health. Care is important as a concept; most people with disability require not just medical care, but both formal and informal social care as well.

Disability has many forms and may present at any age, ranging from a child born with a malformation to an elderly person with dementia. Disability is becoming more common [4]; in the case of dementia, for example, in 2005 it was estimated that 24.3 million people worldwide had dementia, with 4.6 million new cases occurring every year, mostly in developing countries [5]. These epidemiological trends - more elderly people with multiple disease morbidity; more dementia; more young people with disability living longer [6] - must be recognized, and provision made in the health and social-care systems. The complex needs of these different groups need to be understood.

Health care is not just a matter for the health-care system. Much of the health care for the disabled is not delivered by health-care professionals, but by a range of non-medical carers. A family that includes a person with disability will always be affected by the presence of the disability and will almost always provide some-often most — of the care for the health and wellbeing of the family member who is disabled. This varies from one society to another, and the local cultural, economic and social environment must be respected and care provided within that context. Therefore, to improve our understanding of the health needs of people with disability, and through this to improve the health care they are given, we need anthropological [7], sociological and health economic studies relevant to this population. This will help to develop a theoretical understanding of the relevant societal and cultural contexts, and of the political systems and financial resources that are required to support the development of appropriate interventions and the improvement of health care.

The paradigm that dominates the education and practice of health-care workers is to diagnose and cure illness; long-term care, particularly of people with disability, plays a smaller part in the educational curriculum. However, society needs long-term care as well as short-term cure. Medical curricula are changing and there is greater recognition that medicine (and other disciplines) must be more responsive to the needs of society. This was demonstrate by the Global Consensus for
Social Accountability of Medical Schools [8] and reflected in the new, 2012, version of the World Federation for Medical Education standards for basic medical education [9].

It is a fundamental principle in health care that the patient must, as far as possible, understand and give informed consent to his or her treatment. This may be a particular problem in the care of disabled people, if they are unable because of their disability to agree to the treatment that will be best. A nuanced approach to the understanding of which interventions will improve the quality of life for each person with disability is required [10], worked out appropriately for each culture and care setting. The care setting may be at home, in hospital, in a care home or elsewhere.

In summary, to improve the health of people with disabilities we must approach the question in a multidisciplinary and culturally sensitive way, understanding the society in which we are working, and bringing together members of the health-care team, the family and other informal carers. We need to conduct research, both qualitative and quantitative, in medical and social science paradigms, and address the needs of people with disabilities and their families, as well as the attitudes of families and health-care professionals. This will improve the political, economic and societal policy for the pattern of care that is needed.

\section{Acknowledgement}

I am grateful for the expert advice of Dr L. Jones. 


\section{References}

1. The Universal Declaration of Human Rights. United Nations [Internet] (http://www.un.org/en/documents/udhr/, accessed 3 February 2014).

2. WHO Constitution. World Health Organization [Internet] (http://www.who.int/governance/eb/constitution/en/, accessed 3 February 2014).

3. Davies-Stofka B. Suffering and the problem of evil. Patheos Library [Internet] (http://www.patheos.com/Library/Islam/ Beliefs/Suffering-and-the-Problem-of-Evil.html, accessed 3 February 2014).

4. Murray CJ et al. Disability-adjusted life years (DALYs) for 291 diseases and injuries in 21 regions, 1990-2010: a systematic analysis for the Global Burden of Disease Study 2010. Lancet, 2012, 380:2197-2223.

5. Ferri CP et al. Global prevalence of dementia: a Delphi consensus study. Lancet, 2005, 366:2112-2117.
6. Fraser LK et al. Rising national prevalence of life-limiting conditions in children in England. Pediatrics, 2012. doi: 10.1542/ peds.2011-2846.

7. Farmer P. AIDS and accusation: Haiti and the geography of blame. Berkeley, California, University of Press, 2006.

8. Global Consensus for Social Accountability of Medical Schools [Internet] (healthsocialaccountability.org, accessed 3 February 2014)

9. WFME global standards for quality improvement in basic medical education. Copenhagen, World Federation for Medical Education http://www.wfme.org/standards/bme, accessed 3 February 2014).

10. Round J, Sampson EL, Jones L. A framework for understanding quality of life in individuals without capacity. Quality of Life Research, 2013. doi: 10.1007/s11136-013-0500-z/. 